\title{
Identifying of structural elements of building using Ground penetrating radar (GPR): A case study of the Cumhuriyet University, Turkey
}

\author{
Erkan TAŞTAN ${ }^{1}$, Sinan KOŞAROĞLU ${ }^{1 *}$, Funda BİLİM ${ }^{1}$ \\ ${ }^{1}$ Cumhuriyet University, Department of Geophysical Engineering, TR-58140 Sivas, Turkey
}

\section{ART ICLE INFO}

\section{Article history:}

Received 27 February 2017

Received in revised form 04 May 2017

Accepted 12 June 2017

Keywords:

Ground-penetrating radar (GPR)

The Rebar

The Curtain Wall

\begin{abstract}
A B S T RAC T
Ground-penetrating radar (GPR) is one of the most recommended non-destructive methods in identifying of structural elements of building. The B building of the Cumhuriyet University, Engineering Faculty was assessed by using the $1600 \mathrm{MHz}$ antennas. As a result of evaluate of GPR data, the locations, horizontal and vertical interval, radius and corrosion rate of reinforcements in curtain walls is determined. It is proposed that the main reason of the structural changes in the reinforcements may be caused by groundwater.
\end{abstract}

\section{Introduction}

In our country one of the major causes of damage to buildings as a result of the earthquake is not done a reinforcement arrangement correctly. Other cause is corrosion of longitudinal and transverse reinforcements resulted from electro-chemical reaction that occurs from vibration, mechanical fatigue, and external ambient conditions (water leak, ground water, moisture). Corrosion declines the strength of the reinforcement and causes fractured in concrete by increasing the volume of iron. This situation decreases the strength of the building. Ground penetrating radar (GPR) has been used to determine of location of reinforcements, estimate of moisture variations and determine the diameters of rebars in reinforced concrete for the past 20 years (Hugenschmidt, 2002; Dérobert et al., 2008; Chang et al., 2009; Solla et al., 2011; Leucci et al.,
2012; Beben et al., 2013; Varnavina et al., 2015; Koşaroğlu et al., 2016). It can be accessed the theory of GPR from the above mentioned articles. GPR detects electromagnetic discontinuities in the shallow subsurface (about $<20 \mathrm{~m}$ ) by the generation, propagation, reflection and reception of highfrequency electromagnetic pulses (Annan, 2002). The frequency of the electromagnetic signals transmitted by GPR systems typically range between $10 \mathrm{MHz}$ and $2600 \mathrm{MHz}$. The higher frequency systems ( $>1000 \mathrm{MHz}$ ) are generally used for engineering applications such as the detection of reinforcing bars in concrete or infrastructure studies.

In the present study, GPR method was used to investigate some curtain walls selected from the main carrier systems of " $B$ " Building of Engineering Faculty of Cumhuriyet University (Sivas). This study constitutes the second part of Koşaroğlu et al. (2016).

\footnotetext{
* Corresponding author. 


\section{Methodology}

The theory of the propagation of electromagnetic waves is described by Daniels (2004) and will not be covered in details here. But, basic principle and some parameters of GPR are briefly given in this section.

GPR uses electromagnetic (EM) wave to transmit into the subsurface. The transmitted energy is reflected back from an object or interface which has a different dielectric properties than a surrounding material. EM wave propagation is explained by Maxwell's equations and the propagation of EM wave mainly depends on the relative dielectric constant $\left(\varepsilon_{r}\right)$ and electrical conductivity $(\sigma$ ) (Leucci et al., 2012). These parameters affect both EM wave attenuation $(\alpha)$ and wave propagation velocity $(v)$ (Leucci et al., 2012). The attenuation $(\alpha)$ is given as follows:

$\alpha=\omega \sqrt{\varepsilon \mu}\left\{\frac{1}{2}\left[\sqrt{1+\left(\frac{\sigma}{\omega \varepsilon}\right)^{2}}-1\right]\right\}^{0.5}$

Where $\mu=\mu_{0}=4 \pi \times 10^{-7} \mathrm{Hm}^{-1}, \omega=2 \pi f, f$ is the frequency in $\mathrm{Hz}, \varepsilon=\varepsilon_{r} \varepsilon_{0}$, and $\varepsilon_{0}=8.85 \times 10^{-12} \mathrm{Fm}^{-1}$ is the dielectric permittivity of the vacuum. In general, $\varepsilon, \mu$ and $\sigma$ are complex quantities. Equation (1) can be given in terms of real effective permittivity $\mathcal{E}_{e}$ and real effective conductivity ( $\left.\sigma_{e}\right)$. In the low-loss approximation, $\alpha$ can be calculated from (Griffiths, 1989)

$\alpha=\frac{\sigma_{e}}{2} \sqrt{\frac{\mu_{0}}{\varepsilon_{e}}}$

The velocity of EM wave's propagation is calculated from equation (3) for low-loss media (Sharma, 1997).

$v=\frac{c}{\sqrt{\varepsilon_{r}}}$

Where $\mathrm{c}$ is the speed of ligth in vacuum, $c=3 \times 10^{8} \mathrm{~ms}^{-1}$.

For a low-loss aproximation, the reflected part of the EM wave energy at a boundary between two materials with relative permittivities $\varepsilon_{1}$ and $\varepsilon_{2}$ can be given as (Chang et al., 2009)

$$
R=\frac{\sqrt{\varepsilon_{1}}-\sqrt{\varepsilon_{2}}}{\sqrt{\varepsilon_{1}+\sqrt{\varepsilon_{2}}}}
$$

If $\varepsilon_{2}>\varepsilon_{1}$, the reflection amplitude becomes negative $\varepsilon_{2}=\varepsilon_{1}$, there will be no reflection.

There are two resolutions in GPR as the horizontal and vertical. The horizontal resolution is defined as the ability to distinguish two close elements, at the same depths, as different anomalies (Daniels et al., 1988). The horizontal resolution depends on the characteristics of the radar signal (antenna central frequency), the trace interval, the electromagnetic properties of the medium and the distance from the antenna to the target (Daniels et al., 1988). Vertical resolution is usually considered $1 / 4$ of the wavelength. The centre frequency of the received signal is lower than the nominal centre frequency of the antenna.

\section{GPR data and analysis}

Figure 1 and Figure 2 show the location of the Cumhuriyet University campus and the general location plan of "B" Building of Engineering Faculty, respectively. The two-dimensional (2D) GPR data were measured on the $1 \mathrm{~m}$-spaced parallel GPR profiles using $1600 \mathrm{MHz}$ shielded antennas. The antenna parameters used in this study are given in Table 1 . The GPR equipment was the Mala RAMAC. GPR profiles were selected from the curtain concrete reinforcement named as P1, P2, P3, P4, P5, P6, P7 and P8 given in Fig.2. Only four problematic areas (P1, P2, P5, P6) are given as an example in this article (Figs., 3 , $4,5,6)$.

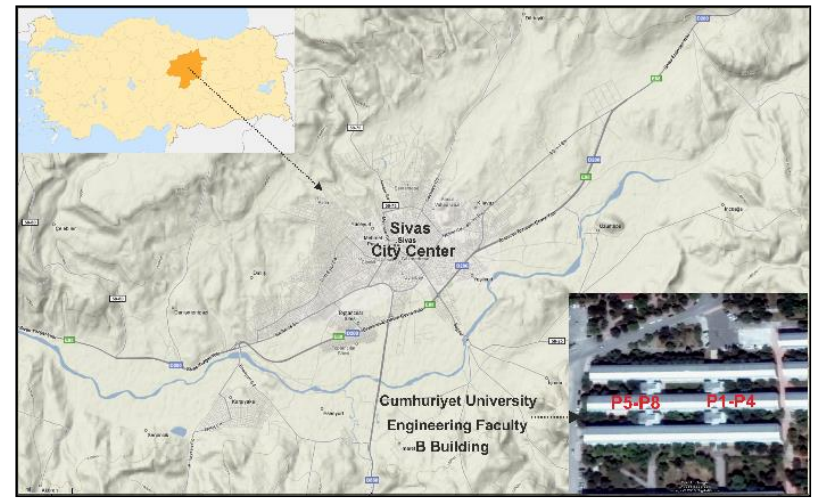

Figure 1. The location map of the study area (taken from Google Earth). 


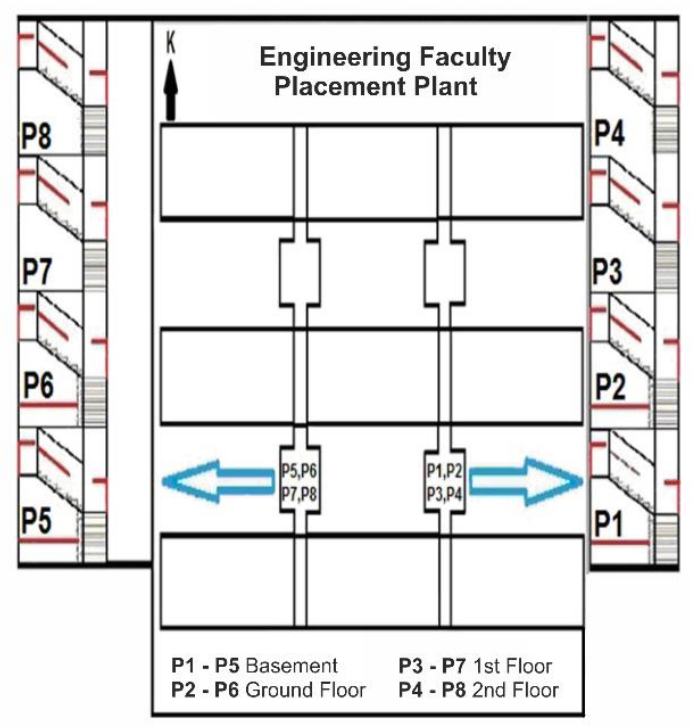

Figure 2. The location plan of the "B" Building of Engineering Faculty and the locations of the GPR profile.

Table 1. Acquisition parameters of the GPR survey.

\begin{tabular}{|c|c|}
\hline Antenna frequency & $1600 \mathrm{MHz}$ \\
\hline Trace interval & $0.01 \mathrm{~m}$ \\
\hline Samples & 267 \\
\hline Sampling frequency & $17372 \mathrm{MHz}$ \\
\hline Time window & $12 \mathrm{~ns}$ \\
\hline Trace numbers & 101 \\
\hline
\end{tabular}

REFLEXW software was used for enhancing the signal. The processing steps were carried out for all the profiles as fallows: 1) time correction; 2) de-wow and background removals; 3) the amplitude attenuations; 4) band -pass filter; 5) velocity analysis and finally, 6) Kirchhoff migration was applied to the radargrams using the mean velocity and transformed the time scale to the depth scale. Then, all the 2D processed profile data were aligned for obtaining 3D data display (Figures 3, 4, 5, 6).

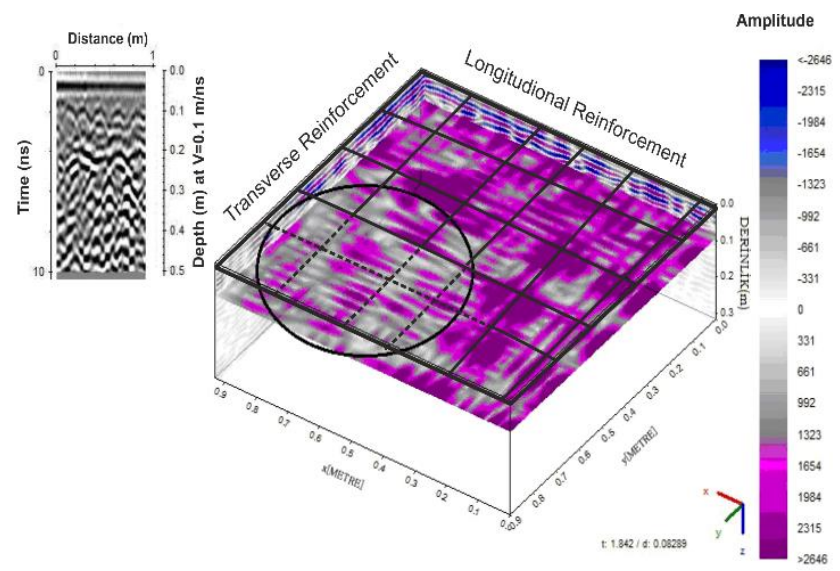

Figure 3. 3D GPR processed image map of $\mathrm{P} 1$ area (P1-3). The elliptical shape shows the corroded area.

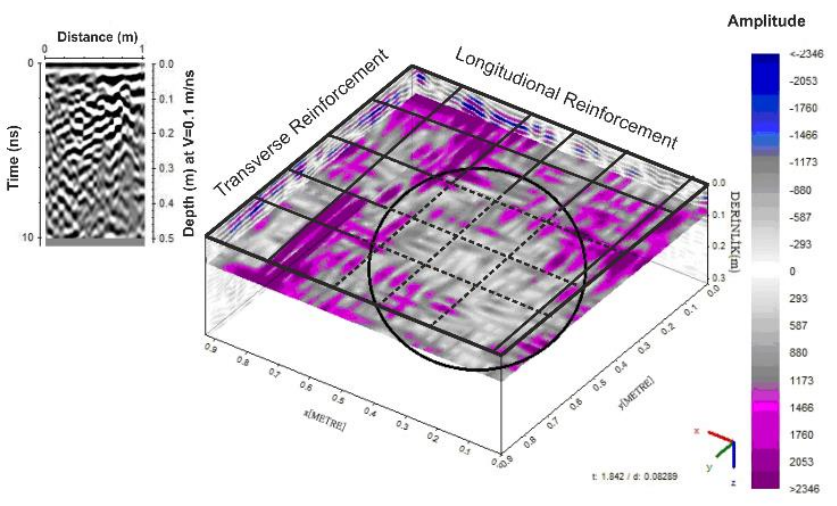

Figure 4. 3D GPR processed image map of $\mathrm{P} 2$ area (P2-3). The elliptical shape shows the corroded area.

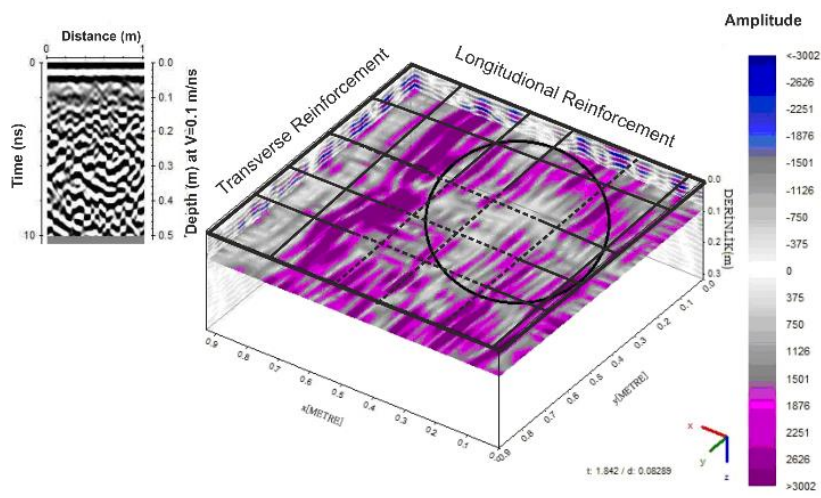

Figure 5. 3D GPR processed image map of P5 area (P5-2). The elliptical shape shows the corroded area.

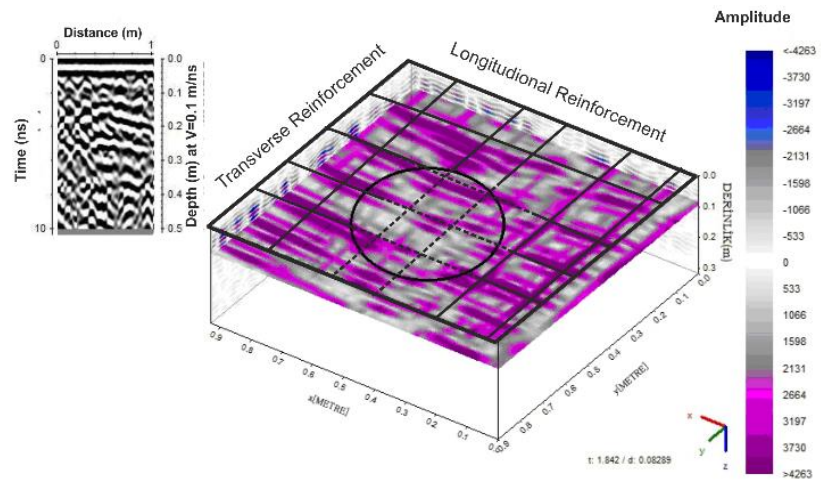

Figure 6. 3D GPR processed image map of P6 area (P6-1). The elliptical shape shows the corroded area. 


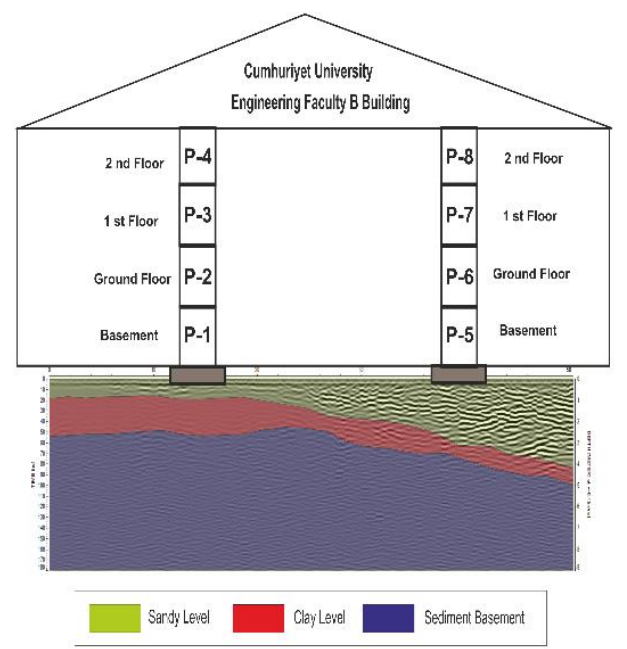

Figure 7. Interpreted GPR profile taken from the basement floor with $250 \mathrm{MHz}$ shielded antenna.

\section{Conclusions}

In this study, it is determined from 3D reconstruction of the horizontal and vertical reinforcement that some reinforcements within the curtain walls in basement and ground floors was corroded resulted from moisture and humidity (Figs., 3, 4, 5, 6 shown with elliptical shape). Furthermore, it can be concluded that while the radius of the rebar are increase, the amplitude of signal is decrease. The radius of the rebar and the amplitude values of signal are given in Table 2.

In general, the range and radius of reinforcement within the curtain-walls in buildings are $\leq 0.20 \mathrm{~m}$ and $\geq 0.08 \mathrm{~m}$, respectively. In addition, the numbers of the horizontal and the vertical reinforcement are 5 pieces. It can be concluded that the P1, P2, P5 and P6 areas of the "B" Building of Engineering Faculty may be firstly damaged in case of an earthquake. The interpreted section of $250 \mathrm{MHz}$ GPR profile taken from the basement floor of the building is given in Fig. 7. The uppermost part of 0 to about $4 \mathrm{~m}$ in depth depicts wavy reflections of high amplitude corresponding to sandy level. The reflections suggests that the thickness of reduces eastward (Fig. 7). Below this, it is suggested that there are two zones distinct reflection pattern from 1 to $4 \mathrm{~m}$ (possibly clay level) and from 4 to $9 \mathrm{~m}$ (possibly sedimentary main rock) in depth.

Table 2. The estimation of diameter of reinforcements, the amplitude of GPR and the posibily cause of deformation determined from all the GPR profile (Fig. 2).

\begin{tabular}{|c|c|c|c|}
\hline AREA & REBAR & $\begin{array}{c}\text { AMPLITUDE } \\
\text { OF } \\
\text { GPR }\end{array}$ & $\begin{array}{c}\text { THE POSSIBLY CAUSE OF } \\
\text { DEFORMATION }\end{array}$ \\
\hline P1(P1-1) & $20 \mathrm{~mm}$ & 2443 & Groundwater (corrosion) \\
\hline P1(P1-2) & $20 \mathrm{~mm}$ & 2456 & Groundwater (corrosion) \\
\hline P1(P1-3) & $20 \mathrm{~mm}$ & 2673 & Groundwater (corrosion) \\
\hline P1(P1-4) & $20 \mathrm{~mm}$ & 2059 & Groundwater (corrosion) \\
\hline P1(P1-5) & $10 \mathrm{~mm}$ & 2895 & Groundwater (corrosion) \\
\hline P1(P1-6) & $18 \mathrm{~mm}$ & 2646 & Climate chance (corrosion) \\
\hline
\end{tabular}

\begin{tabular}{|c|c|c|c|}
\hline P1(P1-7) & $20 \mathrm{~mm}$ & 2197 & Climate chance (corrosion) \\
\hline P1(P1-8) & $20 \mathrm{~mm}$ & 2132 & Climate chance (corrosion \\
\hline P1(P1-10) & $18 \mathrm{~mm}$ & 2910 & Build console (strain) \\
\hline P1(P1-11) & $10 \mathrm{~mm}$ & 2766 & Build console (strain) \\
\hline $\mathrm{P} 2(\mathrm{P} 2-1)$ & $18 \mathrm{~mm}$ & 3216 & Groundwater (corrosion) \\
\hline $\mathrm{P} 2(\mathrm{P} 2-2)$ & $20 \mathrm{~mm}$ & 2940 & Groundwater (corrosion) \\
\hline P2(P2-3) & $20 \mathrm{~mm}$ & 3136 & Groundwater (corrosion) \\
\hline P2(P2-4) & $20 \mathrm{~mm}$ & 3724 & Groundwater (corrosion) \\
\hline P2(P2-5) & $18 \mathrm{~mm}$ & 3002 & Climate chance (corrosion \\
\hline P2(P2-7) & $10 \mathrm{~mm}$ & 3253 & Climate chance (corrosion \\
\hline P2(P2-8) & $20 \mathrm{~mm}$ & 2346 & Build console (strain) \\
\hline P2(P2-9) & $10 \mathrm{~mm}$ & 3760 & Build console (strain) \\
\hline P3(P3-1) & $10 \mathrm{~mm}$ & 2897 & Climate chance (corrosion) \\
\hline P3(P3-3) & $10 \mathrm{~mm}$ & 3282 & Climate chance (corrosion \\
\hline P3(P3-4) & $20 \mathrm{~mm}$ & 4440 & Climate chance (corrosion) \\
\hline P3(P3-5) & $10 \mathrm{~mm}$ & 3894 & Build console (strain) \\
\hline P3(P3-6) & $10 \mathrm{~mm}$ & 3139 & Build console (strain) \\
\hline P4(P4-2) & $20 \mathrm{~mm}$ & 3389 & Climate chance (corrosion \\
\hline $\mathrm{P} 4(\mathrm{P} 4-3)$ & $10 \mathrm{~mm}$ & 3709 & Climate chance (corrosion) \\
\hline P4(P4-4) & $15 \mathrm{~mm}$ & 4101 & Climate chance (corrosion \\
\hline $\mathrm{P} 4(\mathrm{P} 4-5)$ & $10 \mathrm{~mm}$ & 3689 & Build console (strain) \\
\hline P4(P4-6) & $20 \mathrm{~mm}$ & 4442 & Build console (strain) \\
\hline $\mathrm{P} 4(\mathrm{P} 4-7)$ & $10 \mathrm{~mm}$ & 3660 & Build console (strain) \\
\hline P5(P5-2) & $10 \mathrm{~mm}$ & 2467 & Groundwater (corrosion) \\
\hline P5(P5-3) & $20 \mathrm{~mm}$ & 2311 & Groundwater (corrosion) \\
\hline P5(P5-4) & $22 \mathrm{~mm}$ & 2209 & Groundwater (corrosion) \\
\hline P5(P5-5) & $10 \mathrm{~mm}$ & 3351 & Groundwater (corrosion) \\
\hline P5(P5-6) & $20 \mathrm{~mm}$ & 3352 & Climate chance (corrosion \\
\hline P5(P5-7) & $20 \mathrm{~mm}$ & 3525 & Climate chance (corrosion) \\
\hline P5(P5-10) & $10 \mathrm{~mm}$ & 3172 & Build console (strain) \\
\hline P6(P5-11) & $20 \mathrm{~mm}$ & 3632 & Build console (strain) \\
\hline P6(P6-1) & $15 \mathrm{~mm}$ & 3216 & Groundwater (corrosion) \\
\hline P6(P6-2) & $10 \mathrm{~mm}$ & 2276 & Groundwater (corrosion) \\
\hline P6(P6-3) & $10 \mathrm{~mm}$ & 2985 & Groundwater (corrosion) \\
\hline P6(P6-4) & $10 \mathrm{~mm}$ & 4096 & Climate chance (corrosion) \\
\hline P6(P6-5) & $18 \mathrm{~mm}$ & 2854 & Climate chance (corrosion) \\
\hline P6(P6-6) & $10 \mathrm{~mm}$ & 3955 & Climate chance (corrosion) \\
\hline P6(P6-7) & $18 \mathrm{~mm}$ & 3319 & Climate chance (corrosion \\
\hline P6(P6-8) & $10 \mathrm{~mm}$ & 4263 & Build console (strain) \\
\hline P6(P6-9) & $10 \mathrm{~mm}$ & 3856 & Build console (strain) \\
\hline $\mathrm{P} 7(\mathrm{P} 7-1)$ & $18 \mathrm{~mm}$ & 3144 & Climate chance (corrosion \\
\hline P7(P7-2) & $10 \mathrm{~mm}$ & 5156 & Climate chance (corrosion) \\
\hline P7(P7-3) & $18 \mathrm{~mm}$ & 3141 & Climate chance (corrosion) \\
\hline P7(P7-4) & $18 \mathrm{~mm}$ & 3063 & Climate chance (corrosion) \\
\hline P7(P7-5) & $10 \mathrm{~mm}$ & 3682 & Build console (strain) \\
\hline
\end{tabular}




\begin{tabular}{|c|c|c|c|}
\hline P7(P7-6) & $10 \mathrm{~mm}$ & 3415 & Build console (strain) \\
\hline $\mathrm{P} 8(\mathrm{P} 8-3)$ & $18 \mathrm{~mm}$ & 4178 & Climate chance (corrosion) \\
\hline $\mathrm{P} 8(\mathrm{P} 8-4)$ & $10 \mathrm{~mm}$ & 4178 & Climate chance (corrosion) \\
\hline $\mathrm{P} 8(\mathrm{P} 8-5)$ & $10 \mathrm{~mm}$ & 3898 & Build console (strain) \\
\hline $\mathrm{P} 8(\mathrm{P} 8-6)$ & $10 \mathrm{~mm}$ & 3652 & Build console (strain) \\
\hline
\end{tabular}

\section{Acknowledgments}

This work constitutes a partial section of the MSc. thesis undertaken by Erkan TAŞTAN at the Cumhuriyet UniversitySivas-Turkey (supervisor by Prof. Dr. Funda BILIM). The authors also thank to Cumhuriyet University, the Construction and Technical Works Department and the Dean of Engineering Faculty in order to allow collecting the GPR data.

\section{References}

Annan, A. P., 2002. The history of ground penetrating radar, Subsurface Sensing Technologies and Applications, 3(4), 303-320.

Beben, D., Anigacz, W., and Ukleja, J., 2013. Diagnosis of bedrock course and retaining wall using GPR. NDT and E International, 59, 77-85.

Chang, C.W., Lin, C.H., ve Lien, H.S., 2009. Measurement radius of reinforcing steel bar in concrete using digital image GPR. Construction and Building Materials, 23, 1057-1063.

Daniels, D.J., Gundon, D.J., and Scott, H.F., 1988. Introduction to subsurface radar. Radar Signal Process. 135, 278-320.
Daniels, D.J., 2004. Ground-Penetrating Radar 2nd edn (London: The Institution of Electrical Engineers).

Dérobert, X., Iaquinta, J., Klysz, G., and Balayssac, J. P., 2008. Use of capacitive and GPR techniques for the non-destructive evaluation of cover concrete. NDT and E International, 41(1), 44-52.

Griffiths, D.J., 1989. Introduction to Electrodynamics (Englewood Cliffs, NJ: Prentice-hall) (http://www.physicspages.com/indexelectrodynamics/Griffiths-introduction-to-electrodynamics-problems/)

Hugenschmidt, J., 2002. Concrete bridge inspection with a mobile GPR system. Journal Construction and Building Materials, 16(3), 147-154.

Koşaroğlu, S., Taştan, E., ve Bilim, F., 2016. Cumhuriyet Üniversitesi, Mühendislik Fakültesi Binasının Yer Radarı (GPR) yöntemi ile hasarsız incelenmesi. BEÜ Fen Bilimleri Dergisi, 5(1), 77-85.

Leucci, G., Masini, N., ve Persico, R., 2012. Time-frequency analysis of GPR data to investigate the damage of monumental buildings. Journal of Geophysics and Engineering, 9(4), S81.

Sharma, P.V., 1997. Environmental and Engineering Geophysics (Cambridge: Cambridge University Pres) pp 310-328.

Solla, M., Lorenzo, H., Riveiro, B., and Rial, F.I., 2011. Non-destructive methodologies in the assessment of hte masonry arch bridge of Traba, Spain. Engineering Failure Analysis, 18, 828-835.

Varnavina, A.V., Khamzin, A. K., Sneed, L.H., Torgashov, E.V., Anderson, N.L., Maerz, N.H., and Boyko, K.J., 2015. Concrete bridge deck assessment: Relationship between GPR data and concrete removal depth measurements collected after hydrodemolition. Construction and Building Materials, 99, 26-38. 